\title{
Basic skills and transitions to adulthood DONALD SIMPSON
}

School of Social Sciences and Law, University of Teesside, UK MARK CIESLIK

School of Social Sciences and Law, University of Teesside, UK

\begin{abstract}
This article reports on the fi ndings of a qualitative research project conducted in the North East of England. This project involved interviews with 55 young adults in an attempt to explore the impact of poor basic skills on transitions to adulthood. Poor basic skills have been identifi ed across Europe as a problem facing nation states, groups and individuals. But apart from large-scale survey-based studies (Bynner and Parsons, 2001), previous youth research has neglected the process through which basic skills play a role in transitions to adulthood. Proposing a social theory of situated basic skills as communal and individual resources, the authors develop an approach that is sensitive to both structure and agency in theorizing the role of literacy, numeracy and oracy in transitions. They claim that the mobilization of basic skills resources and their role across the life-course can best be understood by using a conceptualization of agency that recognizes the importance of refl exivity as a mediating link between subjective (agential) and objective (structural) dimensions of transition.
\end{abstract}

\section{Keywords}

basic skills, England, literacy, numeracy, youth transitions

Poor basic skills have been identifi ed across Europe as a major problem facing nation states, groups and individuals. European-wide responses include initiatives funded via the European Commission Directorate General for Education and Culture's Socrates programme, for example, the latter funded what was called 'Grundtvig' which was one of eight actions that aimed to enhance adult education provision and to promote a policy of lifelong learning by means of European co-operations. So, for example, the Basic Skills Agency in the UK recently co-operated in Results Exploitation and Project Research and Information on Exclusion (REPRISE), which was funded via Grundtvig and built upon the previous work of the European Basic Skills Network. REPRISE is a project exploring the impact of poor literacy skills whilst sharing and comparing practices and programmes that help to facilitate social inclusion among those with skills deficits. The project has enabled networking between organizations involved in developing policy and practice in the area of basic skills.

REPRISE reveals how definitions of basic skills vary across countries and there is no common understanding of what basic skills constitute. In some European countries definitions adopt a fuller range of competencies needed to live well as individuals and in civil society. These definitions attach importance to interdisciplinary competencies such as foreign languages, Information and Communication Technology (ICT) skills, learning to learn and social skills, a spirit of entrepreneurship (underpinned by a sense of both creativity and initiative) and general cultural abilities and understandings associated with active citizenship (European Association for Education of Adults (EAEA), 2003). In addition to covering 'skills' this more inclusive definition ranges across certain attitudes, aptitudes and knowledge. In other countries a narrower focus is placed on basic skills as only literacy, numeracy and ICT skills.

Nuances in regard to definitions are important because how the concept of basic skills is defined shapes action plans across individual European nation states. In the United Kingdom (UK) a narrow definition of basic skills constituting literacy and numeracy has been adopted. The UK's Basic Skills Agency, for example, defines basic skills as 'the ability to read, write and speak in English/ Welsh and to use mathematics at a level necessary to function and progress at work and in society in general' (DfES, 2003). This article will concentrate on 
the UK context but it is hoped the insights offered will resonate with readers interested in the areas of adult learning and basic skills from across Europe.

At a national level the UK Government launched its Skills Strategy, 21st Century

Skills in July 2003 (DfES, 2003). How to improve basic skills is outlined in a

Skills for Life Strategy and the latter is pervaded by a policy discourse central to knowledge development and learning across late-modern Western European countries - namely, a discourse of economic development through improvements in the skills base. Across the UK it is estimated 'the cost to the country of poor literacy, language and numeracy skills [is] as high as $£ 10$ billion a year' (DfES, 2003).

In meeting the challenge of delivering skills for life, the UK Government's 'goal is to reduce the number of adults with literacy, language and numeracy difficulties'. In England a target of helping 1.5 million adults to achieve a national certificate by 2007 has been set (DfES, 2003). Central to achieving this target will be success in encouraging those that have poor basic skills to re-engage with formal education and learning opportunities. In this context it is important to understand the role of basic skills across the life-course - particularly their role in the processes whereby young people become marginalized and socially excluded. Here there is a problem - academic interest in basic skills has historically remained limited. As a result, it is claimed the new Skills for Life policy in the UK has inherited an 'under-researched' system of adult basic skills (Hamilton, 2001 ) with 'neglect' summing up academic interest in this area (Aldridge and Lavender, 2003).

\section{TRANSITIONS AND BASIC SKILLS}

The profile of young people's skills and education has been raised in recent years with debates about globalization and the need for the 'upskilling' of the workforce (Brown and Lauder, 2001; Kelly, 2005; Spilsbury, 2002). Despite this discussion, as noted there have been few studies into basic skills. The exception has been the survey work of Bynner and colleagues (Bynner and Parsons, 1998; Bynner and Steedman, 1995). Adopting the narrow definition of basic skills as literacy and numeracy popular in the UK, these studies noted how those with poorer skills exhibit greater vulnerability to unemployment, early child bearing, depression and social exclusion (Parsons and Bynner, 2002). Though essential reading, because it focused on baseline and outcome quantitative data, this research was unable to chart how young people actively manage their skill strengths and weaknesses and develop coping strategies which in turn may influence transitions outcomes.

Despite the strong correlation between poor basic skills and negative outcomes revealed by John Bynner and Janet Steedman's (1995) work - especially in the labour market - transitions research generally has not focused in detail on literacy, numeracy and/or oracy and their link as facets of disadvantage with transitions. Rather, although research has examined the role played by a range of structural, cultural and personal factors in the shaping of young people's transitions to adulthood, at best only a cursory glance has been directed to skills. This deficit is evident in European-wide research (Chamberlayne and Wengraf, 2002; European Group for Integrated Social Research (EGRIS) 2001) and recent high profile UK based research programmes such as the Joseph Rowntree Foundation's Young People in Transition programme (Jones, 2002) and the Economic and Social Research Council's Youth Citizenship and Social Change programme (Catan, 2004). In the UK, Andy Furlong et al. (2003) and Andy Furlong and Fred Cartmel (2004) have highlighted how hard and soft skills are associated with low educational attainment and the experience of poor quality work and work-based training. However, they do not move beyond this position to discuss the process by which skills may feature throughout the individual biography, informing key points in the transition to adulthood. 
role in transitions to adulthood. We contend tat this is short-sighted. As we go on to show, skills do have a role in influencing transitions but they do so as basic skills practices rather than as isolated skill competencies. As Barton and others have documented (Barton et al., 2000) individuals employ their skills in relation to interactional processes related to their values, attitudes and features of their social identities. David Barton and Mary Hamilton used this formulation to understand how individuals use literacy practices as situated resources to accomplish everyday tasks such as shopping, cooking and travel. We develop this concept of basic skills practice to understand how different basic skills may have different values for particular individuals in particular settings and hence a differing impact on transition experiences. Depending on the individual employing the skill and the context of use a particular skill may facilitate or constrain particular transition experiences, hence basic skills of individuals may have a particular 'exchange value'.

\section{TRANSITIONS AND REFLEXIVITY}

In the context of 'late-modernity', researchers exploring youth transitions have attempted to develop theoretical understandings that integrate structural influences and the role of the individual (Hubbard, 2000). These researchers have drawn on theories such as 'risk society' (Beck, 1992) and the concept of 'reflexive modernization' (Beck et al., 1994). Put simply, the on-going modernization process is claimed to have altered social organization within Western European countries and resulted in 'manufactured risks' (hazards such as increased job insecurities) as shared life experiences mediated by the market and shaped by social status have begun to break apart. Reflexive modernization at several levels - including that of the individual - is a process of managing risks. Individuals through reflexive modernization reflect, monitor and change (or not) their practices and behaviour while continually gathering information.

Drawing on such theoretical insights youth researchers have reconsidered structure and agency in biographies and two models of transition have become popular - 'structured individualization' (Evans, 2002; Rudd and Evans, 1998) and 'rationalized individualization' (Furlong et al., 2003). The two models operationalize structure and agency in different ways. Structured individualism is underpinned by a 'duality of structure and agency' and has strongly influenced recent European research on youth transitions. Representatives of EGRIS including Andreas Walther and Manuela Du Bois Reymond - claim to integrate the levels of structure and agency in their work. Resonating with Anthony Giddens' 'structuration theory', these authors suggest that within current transitions made by youths in Western European countries the structural properties of social systems provide the means by which people act and they are also the outcome of these actions. 'Active negotiation on the action side corresponds to transforming reproduction on the structural side' (EGRIS, 2001).

Those adopting the structured individualist model in the UK have coined the term 'bounded agency' (Evans, 2002) to indicate how agency is conflated with and inseparable from social milieu in this way. But this conflation is problematic. These authors fail to give a full account of how structural factors and their properties are internalized by agents. So, for example, authors for EGRIS claim that 'young adults permanently create their life-worlds' (EGRIS, 2001). But it is unclear when using this model where an individual young person begins and ends in regard to social context and therefore how can we be sure it is they that are creating their 'life-worlds'. In using the structured individualism model to conceptualize change in individual transitions what is missing is an 'interactive situational dimension' (Mouzelis, 2000).

An alternative conceptualization of structure and agency in youth transitions is provided by Furlong and his colleagues (2003). They use a 'rationalized individualization' model of transitions into adulthood. Like advocates of the structured individualism model Furlong et al. recognize that youth transitions have 
become more like 'navigations' and are 'negotiated' but they maintain a dualism between structure and agency as explanatory concepts. Furlong et al. observe that transition outcomes are the result of a set of resources and contexts that are largely structural (for example, by social class, gender and educational attainment) but that these are 'never secured without some rational intervention by individuals'. This process is described as 'dynamic and reflexive' (Furlong et al., 2003). Unfortunately, Furlong et al. fail to elaborate on the mediatory process that links structural factors, individual agency and reflexivity.

We draw on a model of transition using reflexivity as a mediating link between structural factors and agency in order to clarify the nature of the 'dialectic' pervading the role of basic skills in transitions. This dialectic is between cultural habitus and institutional structures, on the one hand, and the transformative power of individual action, on the other. Our theoretical model of transition shares essential characteristics to the structured individualist model. So we recognize the importance of both an objective and subjective dimension in shaping and transforming the role of basic skills in transitions. However, we offer a different ontological interpretation of the relationship between objective and subjective aspects of transition with regard to their role in transforming individual lives. Rather than confl ating objective and subjective as structured individualism models do, we argue that the autonomous properties and causal powers of real socio-cultural factors on the one hand and those of real thinking and strategizing people on the other, shape transitions but are always mediated via reflexivity. As with the rationalized individualist model, we consider reflexivity as essential.

Reflexivity is 'a personal interior property, with a first-person subjective ontology, and with powers that can be causally efficacious' in regard to individuals and the mobilizing by them of individual and communal basic skills resources (Archer, 2003). The transitions of all the young people interviewed as part of this research illustrate that conditioning in the past - even among individuals sharing similar objective circumstances - can be differential and is implicated in the shaping of diverse concerns and projects amongst individuals. In explaining how circumstance and experiences can have a differential conditioning effect, Margaret Archer (2003) claims individuals engage in an on-going and reflexive 'internal conversation' - that is, self-talk — about (rather than with) the contexts they live within and this 'determines [their] being-in-the-world, although not in the times and the circumstances of [their] choosing' (Archer, 2001). The two cameos that follow will illustrate how this self-talk involved interviewees in a continual process of imagining, reliving, prioritizing, mulling over and planning. So for several of our interviewees a lack of opportunities because of their poor level of basic skills was an objective constraint and concern but their reflexive responses were 'constitutive of [their] concrete singularity' and 'particularized' (Archer, 2001). Despite most of our interviewees having negative experiences of earlier schooling and having poor-level basic skills, each developed distinct concerns, projects and dispositions towards their basic skills which shaped their self-image and identity, the priorities they attached to participation in basic skills training and their plans for future involvement.

Archer categorizes 'internal dialogues' and claims that they take place within different 'modes of reflexivity'. She contends that these modes - communicative reflexivity, autonomous reflexivity, meta-reflexivity and fractured reflexivity - are changeable over the course of a person's life and susceptible to 'fragmentation'. She also notes that other modes may be identified. One of us has demonstrated elsewhere how distinctive forms of actor's reflexive self-talk are used to give meaning to, and in the process activate, the constraints and enablements of the social contexts in which they find themselves with regard to learning identities and participation in formal literacy classes (Cieslik, 2005).

We present two cameos below that will empirically illustrate how those we interviewed strategized (fallibly sometimes) about what they wanted to do and be and about how and if they could achieve their goals (no matter how tentatively 
held). In being reflexive they considered contextually-based structural constraints and enablements. This is not to suggest that those we interviewed were always fully aware of the structural factors that conditioned their transitions - and the role played by basic skills therein - but for all our interviewees subjectively they were aware of their own situations, concerns and projects within these contexts. Across the sample as a whole, reflexive decision-making could be fl awed, not even close to being optimal in addressing concerns and achieving ends attached to projects, and it could have negative consequences for achieving successful transition. But using two cameos as illustrations, we will show how subjective decisions were made by reflexive agents in light of their own resources and concerns within particular contexts.

\section{METHODOLOGY}

A sample of 55 adults aged between 20 and 30 was interviewed between April 2003 and July 2004. These sample members had undertaken basic skills learning in a community college or work setting. This had either been 'embedded' in employment training schemes or was dedicated basic skills provision. In total, 24 men and 31 women were interviewed, and all live in the north east of England in disadvantaged communities. In-depth, qualitative life-history interviews were used (Bertaux and Thompson, 1997; Hubbard, 2000) to construct biographical 'life grids' (Webster et al., 2004) that charted the transition experiences of each individual. These were understood in relation to major career routes such as leisure, school-to-work, family and housing. The research aimed to investigate the relative significance of skill competencies to the structuring of marginal and more successful transitions to adulthood.

Two cameos were selected because they are able to represent some of the most common experiences of those that had made relatively successful and marginal transitions into adulthood. Within our sample there were key differences between those who had pursued marginal careers and those who were more successful. The data supports earlier research which links social background and the structure of opportunities to different transition routes (Furlong et al., 2003; Jones, 2002). The quality of educational provision, employment opportunities and home environment all influenced routes into adulthood. Marginalization was associated with disaffection at school, educational under-achievement, confl ictual parental relationships, early child bearing for young women and intermittent unemployment for the men. The more marginalized moved into social housing and established relationships with individuals from similar disadvantaged social backgrounds. Though not a uni-linear process, interviewees experienced a series of events in different career routes which cumulatively contributed to the process of marginalization or success in transitions to adulthood (Bynner and Parsons, 2005).

Those with 'more successful' transitions had less negative experiences of schooling and better records of attendance and attainment. They also had parents who supported them in their studies. Both males and females pursued further education or training at 16 years of age and were more successful in gaining waged employment and work-based training. The more successful transitions were also associated with less family conflict and parental divorce and family members provided various forms of material and emotional support. Many of the parents of this 'more successful' sample were in waged employment and assisted their children in gaining employment. The more successful women were also more likely to be childless at time of interview or gave birth later than the marginal sample. The more successful also tended to have long-term relationships with partners in waged employment and in some cases had been able to move into privately owned accommodation.

Though we can generalize about relationships between social structures and transitions, we concur with recent research (Webster et al., 2004) that suggests at an individual level there is much diversity between different career routes and much change over biographical time. Some experienced short-lived episodes of 
marginality within their school-to-work careers whilst enjoying much more success in their leisure, housing and domestic careers. The opposite also occurred young people securing employment whilst having restricted leisure experiences and remaining in their home of origin throughout their twenties. The two cameos below show how some of this variability of transition experiences stems from the functioning of basic skills. Although there was evidence that those with a wider range of more severe skill problems experienced more marginal careers, one cannot always predict the effect of a particular skill competency on transition experiences. Basic skills are mediated by other processes and function to influence transitions in indirect ways.

\section{LIVING WITH POOR BASIC SKILLS: Dougie: A 'successful' transition}

Dougie, aged 30 when interviewed, left school at 16 with low grades in national secondary school examinations and 'poor reading and writing' skills. He rarely attended in the final year. He would play truant and do work with a friend's father who was a carpet fitter. After a year doing various jobs he began continual employment as a carpet salesman, fitter and shop worker. He has worked for the same firm ever since. Dougie revealed that his lack of literacy skills had been a constant worry throughout his employment career and resulted in coping strategies, for example, avoidance of basic skill use by getting secretaries to write and type documents which he dictated. His anxiety was lessened over the years however because he observed that others where he worked were 'just as bad' and the firm was 'relaxed' about poor basic skills because an ability to 'do the job' was more important. Dougie noted how a 'gift of the gab' is the 'key to a good salesman'. But following promotion Dougie took on more responsibility, including managing shops. More reading and writing became involved in his job and at an appraisal meeting he decided to reveal his difficulties with these skills. He started attending literacy classes.

Dougie's housing transition was relatively smooth and successful. He moved from the family home about a year after he met his long-term partner, when he was 19 years old. They are buying their house. His basic skills competencies have meant that his partner has taken on many of the basic skills practices attached to responsibilities around managing the home. Dougie noted how his wife is seven years older than him and for several years, until very recently, when it came to filling in forms connected to housing and other issues, he admitted 'l'll get her to do it'. He seemed more concerned that he 'pays his way' by working to afford the mortgage costs. As he noted, 'the wife says to me, "well what would you do if you hadn't met me", and I say "well I couldn't answer that"'.

With regard to his domestic transition and the relations therein, as noted, Dougie had a long-term partner who he met when 18 and had established a relative independence from his family of origin several years before the time of interview. He did not have any children but had a step-daughter. But this transition was certainly eased by the support from his wife who was sympathetic to his difficulties with basic skills and encouraged him to attend basic literacy classes. Over the years he relied on her to do the most rudimentary tasks involved in domestic existence - 'before [attending basic skills classes] l'd get the wife to do birthday cards and Christmas cards'.

\section{Heather: A 'marginal' transition}

As with Dougie, Heather, aged 26 when interviewed, left school with poor grades in national secondary school examinations at 16 . She had a difficult time at school and felt she had been given little support when finding it difficult to read and write. On leaving school, Heather started training as a Care Worker. Despite trying to fulfil her ambition of working with the elderly basic skills problems interfered. When on placement her poor basic skills affected her ability to fulfil her duties. As she recalls: 
'em, there's like a risk assessment if they fall and things like that. You've got like the mobility and you've got everything, the care plans and I 'ad to write a daily report what l've done with 'em in the morning. I couldn't do that... I give a diabetic woman the wrong meal.

It was only after being moved to a youth training centre aged 17 that Heather was diagnosed as being dyslexic. Her mother took on an extra job cleaning to pay for a private tutor specializing in the tuition of those with dyslexia. From this time onwards she regularly attended evening classes doing basic literacy and numeracy courses.

Heather's labour market transition became cyclical and characterized by several short-term and low paid jobs. She eventually found work in a factory and stayed for three years, while continuing to attend basic/key skills classes at a local college. She then left the factory - 'because my career wasn't going anywhere and I wanted to look after the elderly'. Heather looked for work in a care home displaying 'disability symbols' meaning that it will take on staff with learning disabilities and support them. She found employment in such a home but left after three months because the 'disability officer' was verbally abusive - 'she called me retard'. Eventually she found another home and stayed for two and a half years - although she claims it was still a 'struggle', she also pointed out that 'I just stuck it and loved it'. While there Heather completed national vocational qualifications in social care, 'the home got a person to come in and they sat down and divided little segments of work'. When leaving the home Heather started work with a nursing agency and enjoys the variety and discretion around hours that it provides.

Heather continues to live in her parents' home despite her claim that 'I'd love me own house, l'd love to move'. However, she also recognized how her basic skills deficiencies are a major inhibiting factor (and interlink with fi nancial expense and other costs attached to leaving home such as isolation from her family) in regard of her ability to start an independent housing career.

I'd like somebody to say... I'm gonna be somebody still living in the house and you've got problems reading your bills and everything, l'll come around and sit and we'll work it out... Like some things I get through the post from the insurance companies, I cannot understand. I had car accident 2 years ago... and my mam had to sit down and read the letters to me 'cos I don't understand.

Domestically, problems with her speech when younger - Heather had a speech therapist while at school - resulted in her fi nding it hard to make friends. She was bullied at school and felt she would 'never have any friends' — this has seriously impacted on her leisure career. When at school she recalled, 'I had reading andspelling problems. I couldn't speak at the time properly. I found school diffi cult and a lot of people called me names and bullied me'. By her later teens she noted, 'with my dyslexia I was 18 , I acted like a 14-year-old 'cos me mind's not catching up with my body so like when they were 18 years old, I was acting like a 15-year-old. They couldn't handle me being stupid'. She had little success in making friends and meeting potential long-term partners. 'I've had a few boyfriends but I didn't mention I'm dyslexic, but after a while they found out, they took the mick out of me'. When 21 years old Heather was raped - the offender receiving a lengthy prison sentence - and this added to her sense of isolation and low self-esteem. Despite her problems Heather continues to have a very strong bond with - and reliance upon - her immediate family. Heather has also recently been lucky enough to find a supportive and caring partner - 'he loves me the way I am, he supports me with me reading and writing, he helps me to read and write'.

\section{DISCUSSION}

This description of Dougie and Heather's biographies illustrates how basic skills take on an important on-going contributory role in shaping transitions to 
adulthood via basic skills events - observable activities that involve literacy, numeracy and/or oracy. These basic skills events always take place in specific social contexts and are shaped and arise from basic skills practices - socio-culturally conditioned (but as will be argued not determined) ways of utilizing basic skills. We claim below that it is impossible to fully appreciate the role of basic skills events and practices across Dougie and Heather's life-course without considering the objective properties and causal powers of socio-cultural factors on the one hand and the subjective powers of the two interviewees as real thinking and strategizing people on the other.

\section{Basic skills, 'conditions of choice' and transitions}

The two cameos reveal how over time basic skills were intrinsic to helping and hindering attempts by our interviewees to attain certain statuses broadly agreed to be illustrative of successfully reaching adulthood (for example, secure employment and independent living). But the two cameos also confirm that - while poor basic skills are correlated with negative outcomes across the life-course within this relationship poor skills are not neutral technologies with a predetermined mechanically positive or negative impact. Several interviewees in our sample had a higher level of reading, writing and arithmetic than Dougie but his overall transition was more successful. The first step to understanding why is to recognize that basic skills are communal and individual resources whose practice is always 'situated' (Barton et al., 2000).

Socio-cultural (and spatial and temporal) situations are a significant aspect of the 'conditions of choice' that define basic skills events which in turn shape practices and the role attached to them in transitions. Dougie and Heather's cameos show how differing basic skills practices were valorized across the different situations in which they pursued their various strands of transition. In this way, for both interviewees basic skills events and practices and their role were infl uenced by the control systems, common values and norms of the social institutions (for example, work and family) in which they were situated. There are some situations where the 'use value' of a basic skill is readily apparent. Where individuals in our sample, such as Heather, had multiple skill problems these events were more common and were associated with more marginal career routes. Existing research has tended to focus attention on these simpler relationships between poor skills and transitions (Bynner and Parsons, 1997). Other studies have suggested that there is no clear link between skill competences and particular transition outcomes (Furlong and Cartmel, 2004). Instead of discounting the explanatory potential of basic skills we suggest they work in more complicated ways to influence transitions.

Using work institutions as an example illustrates this point. The basic skills practices favoured in Dougie's work context were those concerned with an oral culture and his 'gift of the gab' gave him an advantage in this situation because it compensated for his low literacy skills which were not as valued in this context. In coping with his poor literacy at work Dougie developed a practice of concealment (for example, getting others to write things for him when necessary) that was successful for several years. Following preferment writing became a greater part of his role and openness about his problems and a determination to tackle them eventually became part of his literacy practices. In contrast after initial problems writing at work the requirements of Heather's position as a career for the elderly meant that she could not conceal her difficulties. She moved jobs and for several years her literacy practices were characterized by avoidance of reading and writing in the work domain while she worked in a factory where she did not use her basic skills.

Common norms and values informed communal basic skills practices and the latter existed in the relations between people within social institutions (Barton et al., 2000). Indeed, our interviewees drew on communal basic skills resources found in work-based and kinship networks and these helped infl uence their 
individual practices. Both interviewees described basic skills events where the mobilization of this 'social capital' had facilitated an improved transition experience, for example, in the labour market but also domestically. But in its communal form basic skills resource could also potentially have a delimiting infl uence on transitions by deterring individuals from becoming more independent, for example, Dougie noted how he was 'comfortable' in relationships with work colleagues with literacy competencies 'worse than mine'. Because of this he revealed, 'I don't like change... I'm scared to go out in the big wide world.' Similarly despite wanting to move from her parental home Heather recognized the cost of leaving her parent's home would be unacceptable mainly because she would be removed from the support networks in which she was comfortably embedded with basic skills practices and resources.

Social institutions and relationships condition basic skills practices (Barton et al., 2000). Dougie and Heather's basic skills practices changed over time with new ones being acquired through processes of what Barton and his colleagues term 'informal learning and sense making'. Our evidence supports this theoretical supposition but the relationship suggested between context and the changing basic skill practices of individuals by Barton et al. is vague. They merely state that 'learning and sense making' takes place in 'social contexts' and involves 'the internalization of social processes' (Barton et al., 2000). This suggests a form of 'structured individualism'. But it is important to recognize that Dougie and Heather used creative action in mobilizing basic skills resources as part of their transitions. This subjective dimension is important and more than simply an adjunct to objective dimensions. Both Dougie and Heather learnt informally from basic skills events and one consequence of this was a recognition that their practices would need to change. But this was more than simply a reflex to their own competencies clashing with literacy practices structured and sustained by work and other institutions. Rather their responses were reflexive and involved intentionality and specific goals.

\section{Basic skills, reflexivity and transitions}

Changing basic skills practices and their role in the transitions of Dougie and Heather involved a subjective dimension. This can be demonstrated by looking at Dougie and Heather's differential responses to what can be termed critical basic skill events. Within their biographies it is possible to distinguish between routine and critical basic skills events. The importance of critical events generally is well documented through transitions literature (Thomson et al., 2002; Webster et al., 2004). Routine basic skills events cumulatively helped inform routine basic skills practices and reinforced identities - particularly learning identities — linked to them. Routine basic skills events became critical when they resulted in Dougie and Heather recognizing their importance and considering the consequences of particular decisions and actions with regard to future basic skills practices. Therefore, interviewees' agency, namely, their motivation, pro-activity, concerns, rationalizing, intentions and creativity were important. Interviewees' basic skills practices changed for specific purposes and these were embedded in wider goals that could shift over time. For both Dougie and Heather critical basic skills events resulted in them questioning the logic that shaped their basic skills practices and this resulted in subjective decision-making and strategizing associated with developing new practices to meet ends attached to life projects - this was most obvious in regard to work projects. Both, reflexively and strategically adjusted their literacy practices to enable them to do (and be) what they cared about most.

For Dougie, a project of securing his promotion and place as a 'company man' (the term he uses to label himself) was paramount. This project shaped his return to formal education and attendance at literacy classes. As Dougie observed, 'I get out of it what I want to get out of it, just basic English'. This strategic position was not simply a non-conscious, non-calculating refraction of his social origin and changing work position following promotion. Rather, he demonstrated a 
capacity for reflexive deliberation with regard to concerns he had connected to this life project. He had weighed up the 'opportunity costs' surrounding his promotion and his re-engagement with formal education. The role he attached to his changing basic skills practices as part of his transition was very much a product of subjective reflexive deliberations and strategizing over his work project in relation to his objective circumstances:

I've got no [qualifications from school]... They're [his employers] not interested in what l've got... Y'know... I could go and do a diploma in Maths and a diploma in English and a diploma in this, but... it's not gonna achieve me nothing in work, is it? Not gonna get me any further in life, somewhere else — maybe - but not here [in his current employment].

For Heather, initial attempts to secure a position as a care assistant in homes for the elderly were thwarted by her poor basic skills but she did not lose sight of this project and goal. She observed that she got to a point while working in a factory where, 'I'm thinking, oh well I need better employment so I need to get qualifications to get me employment... because me [work] career wasn't going anywhere'. This was the rationale underpinning Heather's return to complete basic skills classes at evening college while she worked during the day at the factory. These were opportunities that were available and she responded to them with a clear and distinctive rationale. This was also the case when a network of employers willing to support those with learning disabilities and poor basic skills into and through employment (those with 'disability symbols') emerged. This local opportunity structure was essential to Heather's transition pathway but it only became enabling in this way because it dovetailed with Heather's project of working with the elderly and she exercised agential powers in responding to its existence.

So, basic skills events and practices were situated in social contexts that helped shape their nature, the responses of interviewees to them and the role interviewees attached to changes in their practices in regard to transitions. However, they were also located within individual life projects. In pursuing the desired ends attached however tentatively to their respective projects Dougie and Heather both followed courses of action that required changes in their basic skills practices. Across both cameos these changes in practice were planned and designed to re-configure the role of basic skills so that they could better achieve ends. For Dougie and Heather - despite an initial reticence - this process involved a return to formal education after several years away, in an attempt to develop further one or more of their basic skills. In Dougie and Heather's biographies, the development of basic skills practices and the role attached to them reflected personal concerns, preferences and choices and were reflexive rather than simply a reflex.

\section{CONCLUSION}

With regard to young adults, our interviews revealed that basic skills play a continual role in transitions to adulthood. But basic skills are not neutral competencies and a theory of their role in transitions needs to conceptualize them more broadly. Rather, basic skills are individual and communal resources and can have particular 'exchange value' depending on differing situations. Agents mobilize these resources via basic skills events using basic skills practices. Basic skills events can be routine or critical and the latter lead to re-shaping of subsequent practices and can potentially have an influence on transition pathways. Both routine and critical basic skills events, the generation of new basic skills practices and their role as part of individual transitions are always 'situated' and conditioned in two ways.

This is simultaneously within social, spatial and temporal contextual circumstances and within individual life projects. With regard to contextual circumstances, recent transitions research has emphasized how generally social practices of young people (and therefore by inference basic skills practices and their role) 
are pre-dominantly structurally shaped. These explanations claim that despite having poor skills, vulnerable young people can often find work but this is usually within insecure sectors of the labour market, and this work often provides very little training that moves beyond the immediate demands of the tasks for which the workers are employed. These authors then suggest that such contexts largely shape and constrain individual basic skills practices and therefore their role in labour market transitions is largely determined by extraneous circumstances with individuals having limited influence.

But Dougie and Heather's biographies question such empirical generalizations and point to defects in using the structured individualism model of transition when it comes to explaining the changing role basic skills can play across individual life courses. In considering our evidence we claim that it is only through recognizing the importance of agency that we can offer a more powerful explanation for the role of basic skills in Dougie and Heather's transitions. Agency allows us to recognize how Dougie and Heather are reflexive individuals with concerns attached to life projects. As such their subjectivity is also important in informing and defining the role of basic skills events and practices within their transitions.

Utilizing basic skills resources via life projects results in individual basic skills practices being placed in a relationship of harmony or conflict with wider contextual factors (including wider socio-culturally patterned communal basic skills resources) and it is only then that these wider factors become perceived as constraining or enabling as contexts are mediated by reflexive agents who make decisions to alter their existing practices and the role they play. As was shown, central to Dougie and Heather's thinking in regard to the utilization of basic skills resources was the role they could play in regard to meeting their concerns attached to life projects. This is not to downplay the importance of structural factors - rather it is to recognize that both structure and agency are important in informing the role of basic skills across transitions.

The findings of our study contrast with an assumption implicit within European discourses about poor basic skills and their role in youth transitions including the UK's Skills for Life (DfES, 2003) policy. This hypothesis suggests that good/poor basic skills impact in a mechanical way as young people move into adulthood, particularly with regard to labour market participation and the securing of a full adult income and secure employment. Rooted in human capital theory it is assumed that by not investing in one's basic skills negative outcomes are inevitably forthcoming. But our data refutes such a claim and suggests it is an oversimplifi cation. Individual's basic skills competence levels (as a personal resource) are infl uential but they do not always necessarily determine positive or negative outcomes in transitions. The sociological theory we have proposed earlier helps understand why.

As noted in the introduction, European basic skills policy discourses are imbued with notions of economic development. So in the UK 'employer's needs' are placed 'centre stage' in the new national teaching, learning and assessment infrastructure for adult basic skills. But this sits uncomfortably with interviewees' rationale for participation at basic skills classes. Just to recall what Dougie noted 'I want to get out of it what I want to get out of it'. In the UK it is reported that 'the Government's skills strategy has not attracted large numbers of people who would not otherwise have started college courses' (Education Guardian, 2005).

This failure is not surprising because it is one of the policy interventions that the UK Social Exclusion Unit notes 'have not placed suffi cient weight on young people's thinking and behaviour when they have been designed' (Social Exclusion Unit (SEU), 2005). By recognizing the importance of agency and refl exivity, our evidence suggests that formal provision and learning opportunities overly focused on 'employer's needs' rather than on the people attending, their thinking with regard to basic skills and life projects and how these are placed within often complex 
circumstances are unlikely to be appreciated - even when such opportunities are provided free of charge to those with poor skills. This is a central message that has come from our interviewees all of whom were recipients of basic skills learning provision when we met them.

\section{Acknowledgement}

This one year project, The Role of Basic Skills in the Extended Transitions of Young Adults, began late in 2003 and is funded by the Economic and Social Research Council (ESRC grant no. RES-000-22-0331).

\section{References}

Aldridge, Fiona and Lavender, Peter (2003) 'Legacy of Neglect in Adult Basic Skills', Adults Learning 15(4): 26-7.

Archer, Margaret (2001) Being Human: The Problem of Agency. Cambridge: Cambridge University Press.

Archer, Margaret (2003) Structure, Agency and the Internal Conversation. Cambridge:

Cambridge University Press.

Bertaux, Daniel and Thompson, Paul (1997) Pathways to Social Class: A Qualitative Approach

to Social Mobility. Clarendon Press: Oxford.

Barton, David, Hamilton, Mary and Ivanic, Roz (2000) Situated Literacies: Reading and

Writing in Context. London: Routledge.

Beck, Ullrich (1992) Risk Society: Towards a New Modernity. London: Sage Publications. Beck, Ullrich, Giddens, Anthony and Lash, Scott (1994) Refl exive Modernisation: Politics, Traditions and Aesthetics in the Modern Social Order. Cambridge: Polity.

Brown, Phillip and Lauder, Hugh (2001) Capitalism and Social Progress. London:

Palgrave.

Bynner, John and Parsons, Samantha (1997) It Doesn't Get Any Better: The Impact of Poor Basic Skills on the Lives of 37 Year Olds. London: Basic Skills Agency.

Bynner, John and Parsons, Samantha (1998) Use It or Lose It: The Impact of Time out of Work on Literacy and Numeracy Skills. London: Basic Skills Agency.

Bynner, John and Parsons, Samantha (2001) 'Qualifi cations, Basic Skills and Accelerating Social Exclusion', Journal of Education and Work 14(3): 279-91.

Bynner, John and Parsons, Samantha (2005) New Light on Literacy and Numeracy:

Preliminary Report. London: National Research and Development Centre for Adult

Literacy and Numeracy.

Bynner, John and Steedman, Janet (1995) Diffi culties with Basic Skills: Findings from the 1970 Birth Cohort Study. London: Basic Skills Agency.

Downloaded from http://you.sagepub.com at University of Teeside on February 21, 2010

Simpson and Cieslik Basic skills and transitions to adulthood $\mathbf{4 1 1}$

Young 15:4 (2007): 395-412

Catan, Liza (2004) Becoming Adult: Changing Youth Transitions in the Twenty-First Century. Brighton: Trust for the Study of Adolescence.

Chamberlayne, Prue and Wengraf, Tom (eds) (2002) Biography and Social Exclusion in Europe. Bristol: The Policy Press.

Cieslik, Mark (2005) 'Refl exivity, Learning Identities and Adult Basic Skills in the UK', British Journal of Sociology 27(2): 237-50.

Department for Education and Skills (DfES) (2003) Skills for Life: Focus on Delivery to

2007. Nottingham: Department for Education and Skills Publications.

Education Guardian (2005) 'Poor test results', 25 January 2005.

European Group for Integrated Social Research (EGRIS) (2001) 'Mislead Trajectories:

Transition Dilemmas of Young Adults', Journal of Youth Studies 4(1): 101-18.

European Association for Education of Adults (EAEA) (2003) 'Developing Skills for the

Knowledge Economy', URL (consulted December, 2006): http://www.eaea.org

Evans, Karen (2002) 'Taking Control of Their Lives? Agency and Young Adult Transitions

in England and the New Germany', Journal of Youth Studies 5(3): 245-70.

Furlong, Andy, Cartmel, Fred, Biggart, Andy, Sweeting, Helen and West, Patrick (2003)

Youth Transitions: Patterns of Vulnerability and Processes of Social Inclusion.

Edinburgh: Scottish Executive.

Furlong, Andy and Cartmel, Fred (2004) Vulnerable Young Men in Fragile Labour Markets:

Employment, Unemployment and the Search for Long Term Security. York:

JRF Publications.

Hamilton, Mary (2001) 'Progress in Adult Literacy: A Critique', Adults Learning 12(10):

12-4.

Hubbard, Gill (2000) 'The Usefulness of In-depth Life History Interviews for Exploring the Role of Social Structures and Human Agency in Youth Transitions', Sociological Research Online 4(4), URL (consulted May, 2005): http://www.socresonline.org.uk/ 
4/4/hubbard.html.

Jones, Gill (2002) The Youth Divide: Diverging paths to adulthood. JRF Young People

Programme. York: York Publishing Services.

Kelly, Ruth (2005) 'Skills for Life: the Challenge for 2010', Secretary of State's Speech to

the National Skills for Life Conference, 11 November 2005, York.

Mouzelis, Nicos (2000) 'The Subjectivist-Objectivist Divide: Against Transcendence',

Sociology 34(4): 741-62.

Parsons, Samantha and Bynner, John (2002) Basic Skills and Social Exclusion. London:

Basic Skills Agency.

Rudd, Peter and Evans, Karen (1998) 'Structure and Agency in Youth Transitions: Student Experiences of Vocational Further Education', Journal of Youth Studies 1(1): 63-79.

Social Exclusion Unit (SEU) (2005) Transitions: A Social Exclusion Unit Interim Report on Young Adults. London: Offi ce for the Deputy Prime Minister.

Spilsbury, David (2002) Learning and Training at Work Survey 2001, DfES Research Report, RR334. London: Department for Education and Skills.

Thomson, Rachel, Bell, Robert, Holland, Janet, Henderson, Shelia, McGrellis, Sheena and Sharpe, Sue (2002) 'Critical Moments: Choice, Chance and Opportunity in Young People's Narratives of Transition', Sociology 36(2): 335-54.

Webster, Colin, Simpson, Donald, MacDonald, Robert, Abbas, Andrea, Cieslik, Mark, Shildrick, Tracy and Simpson, Mark (2004) Poor Transitions: A Critical Case Study of Young Adulthood and Social Exclusion. Bristol: The Policy Press 